\title{
Influence study of a new 220kV Substation access on regional power grid
}

\author{
Yongchun $\mathrm{Su}^{1, \mathrm{a}^{*}, \text { Xiaoming Wang }}{ }^{2, \mathrm{~b}}$ and Zhan Shu ${ }^{1, \mathrm{c}}$ \\ ${ }^{1}$ JiangXi electric power research institute, NanChang 330096, China \\ ${ }^{2}$ JiangXi electric power company, NanChang 330006, China \\ asuyongchun@126.com, bwangxiaoming@126.com, csuzhan2003@126.com
}

Keywords: Ganzhou power grid; substation; stability calculation.

Abstract. With the application of the original Central Soviet area revitalization planning, the load in Ganzhou area of Jiangxi province will have much increase. In this paper, two schemes on how the $220 \mathrm{kV}$ Wanluo substation connects into the main grid are introduced. The influence of each scheme is analyzed on power flow, transient stability and voltage stability calculation. The analysis result show that the first scheme is better and the operation of $500 \mathrm{kV}$ Fuzhou-Hongdu line will remarkable affect the result. Finally the system voltage stability problem is also analyzed.

\section{Introduction}

To commit the society power demand is the nature function of power grid. With the application of the original Central Soviet area revitalization planning, the load in Ganzhou area of Jiangxi province will have much increase in Jiangxi power network. At the end of 2015, a new 220kV substation will be constructed in west Ganzhou to support the load increase of Shangyou County.

The new substation access will bring impact on original system. Different access mode of the substation will have different effect. In order to ensure the safe and stable operation of the power system, the substation access scheme is required to be evaluated [1-5].

In this paper, calculation and analysis are carried out on a new $220 \mathrm{kV}$ Wanluo substation access to Jiangxi Ganzhou power grid. Influence on regional power grid is evaluated from the aspect of power flow calculation, stability check and voltage stability. The works in this paper provide technical support for the construction and development of the regional power grid.

\section{Boundary Conditions}

Present Situation of Ganzhou Power Grid. At present, Ganzhou power grid connects with the main system by the $500 \mathrm{kV}$ Wenshan-Ganzhou (Wengan) double circuit line and 220kV Wanan-Yanfeng (Wanyan) line, Wanan-Hugang (Wanhu) double circuit line and Jingangshan-Butou (Jingbu) line. The current wiring diagram of Ganzhou power grid is shown in Fig. 1. The total system installed capacity of Ganzhou power supply is 790MW (including Ruijin thermal power plant 2x350MW, Shangyou River hydropower plant 90MW). The peak load in Ganzhou power grid reached 2085MW (at February 2, 2015) and there is large demand for electricity.

Variation of the Power Netword. The structure of Ganzhou power grid will be greatly improved in the next two years: $500 \mathrm{kV}$ Hongdu substation (1x750MVA) will be newly constructed which will connect $500 \mathrm{kV}$ Ganzhou substation with single line. Two $220 \mathrm{kV}$ substations of Wanluo and Guandaoping will also be newly constructed in $220 \mathrm{kV}$ power grid. In 2016 , a new $500 \mathrm{kV}$ power line will be constructed from Fouzhou to Hongdu substation and it will become the second power transmission channel to Ganzhou area.

Load Level. Taking into account the international and domestic economic development situation, the maximum Ganzhou load of 2690MW is used in the following calculations. 


\section{Evaluations on 220kV Wanluo Substation Access Schemes}

According to Wanluo substation position, there are two access modes of Wanluo substation: (1) Connection mode A: access into the $220 \mathrm{kV}$ power line from Wanan to Yanfeng; (2) Connection mode B: access into 220kV Leigongshan-Yanfeng (Leiyan) line.

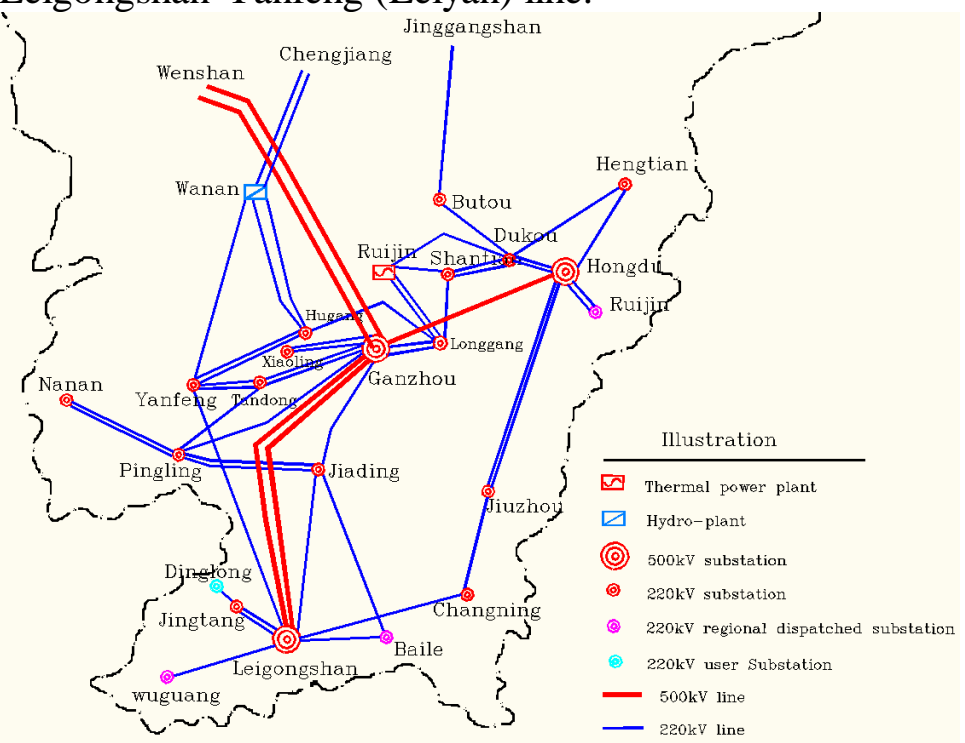

Fig. 1 Diagram of current Ganzhou power grid

According to the power grid planning, the structure of Ganzhou power grid in 2016 is shown in Fig. 2. As the $220 \mathrm{kV}$ substation mainly affect the regional power grid, the following analysis will pay more attention to Ganzhou power network. The sensitivity analysis of 500kV Fuzhou-Hongdu (Fuhong) line access is also carried out.

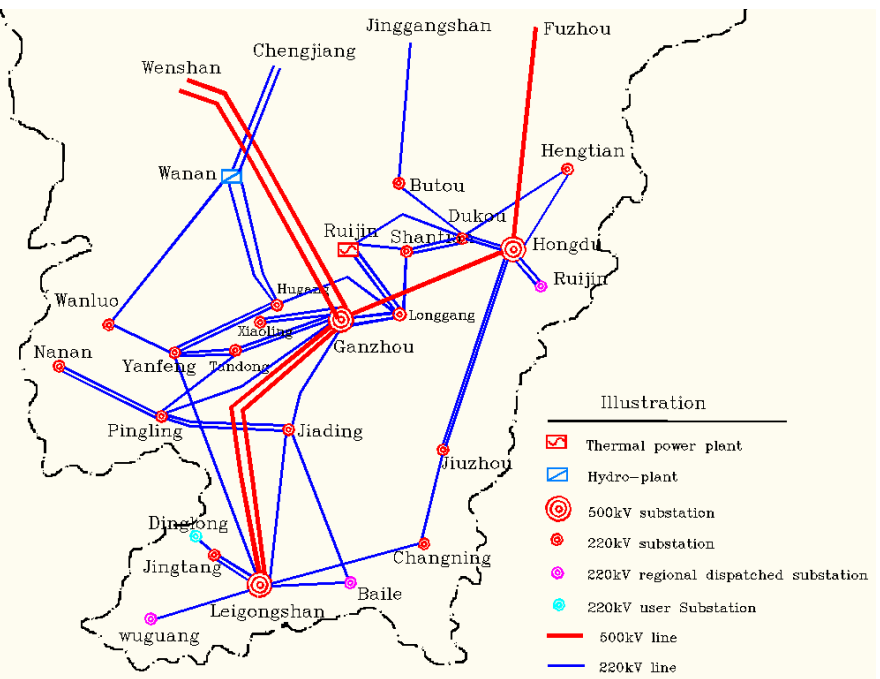

Fig. 2 Diagram of Ganzhou power grid in 2016

In the calculation process two start-up mode of the generators are considered: (1) Generators start-up mode 1: Ruijin 2x350MW, Wanan 4x105MW, Jinggangshan 2x300MW+660MW. (2) Generators start-up mode 2: Ruijin 2x350MW, Wanan 2x105MW, Jinggangshan 1x300MW+660MW. In the second generators start-up mode, less local generators will put into operation.

Connection Mode A. Power flow calculation. Generators start-up mode 1: The power transmission through Ganzhou section is $1979 \mathrm{MW}$ by $500 \mathrm{kV}$ Wengan double circuit line, Fuhong line and 220kV Wanan-Wanluo (Anluo) line, Wanhu double circuit line and Jingbu line. The main transformer load in Ganzhou substation and Leigongshan substation is relatively uniform. Fault on any component such as a transmission line or a transformer will not bring other component overload or the system low voltage (these calculations named "N-1" check). 
Generators start-up mode 2: In this situation, the power transmission through Ganzhou section is also 1979MW. When "N-1" occurs on the main transformer in 500kV Hongdu substation, the transformer load of Ganzhou substation reach its high limit (738MW).

Stability calculation. Stability criterion level 1: When three-phase short circuit or no fault tripping occurs on the main components of Ganzhou section and the substation main transformer, the system remains stable. These components include $220 \mathrm{kV}$ Anluo line, $500 \mathrm{kV}$ Wengan double circuit line, Ganzhou-Leigongshan (Ganlei) double circuit line, 220kV Wanhu double circuit line, Jingbu line, medium voltage side of the main transformer in 500kV Ganzhou substation, Leigongshan substation and Hongdu substation.

Stability criterion level 2: When three-phase short circuit or no fault tripping occurs on $220 \mathrm{kV}$ bus in $500 \mathrm{kV}$ Ganzhou substation, Leigongshan substation and Hongdu substation, the system keeps transient stability. When $500 \mathrm{kV}$ Wengan double circuit lines tripping at the same time, $220 \mathrm{kV}$ lines of Ganzhou section will not overload. When 500kV Ganlei double circuit lines tripping, the system keeps transient stability. But the main transformer in Ganzhou substation will overload (773MW) and stability control must be applied by reducing part of Ganzhou load.

Sensitivity analysis on Fuhong line operation. The analysis above is based on the access of $500 \mathrm{kV}$ Fuhong line. If Fuhong line don't put into operation, the analysis result will be different. The following analysis is based on no operation of Fuhong line.

(1) Power flow calculation: in generators start-up mode 1, when the main transformer in Ganzhou "N-1" or Ruijin generators "N-1", some of the lines and main transformers will overload. In generators start-up mode 2, the main transformer in Ganzhou substation will overload (780MW) when Ruijin generators "N-1".

(2) Stability calculation: The systems keep stable under stability criterion level 1 . Under stability criterion level 2, when 500kV Ganlei double circuit lines tripping, the system remains transient stability, but the Ganzhou main transformer will seriously overload (1080MW). In this situation, stability control of load shedding must be applied in Ganzhou area.

Connection Mode B. Power flow calculation. Generators start-up mode 1: The power transmission through Ganzhou section is $1981 \mathrm{MW}$ by $500 \mathrm{kV}$ Wengan double circuit line, Fuhong line and $220 \mathrm{kV}$ Wanyan line, WanHu double circuit line and Jingbu line. The main transformer load in Ganzhou and Leigongshan substation is relatively uniform. "N-1" check calculation on each component indicates that no transmission line or transformers overload.

Generators start-up mode 2: The power transmission through Ganzhou section is also 1981MW. The transformer in Ganzhou substation will overload (742MW) when "N-1" occurs on the main transformer in 500kV Hongdu substation.

Stability calculation. Stability criterion level 1: When three-phase short circuit or no fault tripping occurs on the main components of Ganzhou section and the substation main transformer, the system remains stable.

Stability criterion level 2: When three-phase short circuit occurs on $220 \mathrm{kV}$ bus in Ganzhou substation, Leigongshan substation or Hongdu substation, the system keeps transient stability. When $500 \mathrm{kV}$ Wengan double circuit lines tripping, $220 \mathrm{kV}$ connecting line of Ganzhou section will not overload. When 500kV Ganlei double circuit lines tripping, the system keeps transient stability. But the main transformer in Ganzhou substation will overload (816MW) and stability control must be applied by load shedding.

Sensitivity analysis on Fuhong line operation. The following analysis is based on Fuhong line not in operation.

(1) Power flow calculation: In generators start-up mode 1, when the Ganzhou main transformer "N-1" or Ruijin generators "N-1", some of lines and main transformers will overload. In generators start-up mode 2, the main transformer in Ganzhou substation will overload (789MW) when Ruijin generators "N-1".

(2) Stability calculation: The systems keep stable under stability criterion level 1. Under stability criterion level 2, when 500kV Ganlei double circuit lines tripping, the system remains transient stability, 
but the Ganzhou main transformer will seriously overload (1092MW). In this situation, stability control of load shedding must be applied in Ganzhou area.

Voltage Stability Analysis. (1) Connection mode A: Stability criterion level 1: No matter 500kV Fuhong line access or not, the system do not have voltage stability problem when any component "N-1".

Stability criterion level 2: If $500 \mathrm{kV}$ Fuhong line in operation, there will be no voltage stability problem in Ganzhou power grid. If 500kV Fuhong line do not put into operation, the system will have voltage stability problem only when the $500 \mathrm{kV}$ Wengan double circuit lines tripping without stability control measures. The $500 \mathrm{kV}$ bus voltage variation in Ganzhou substation is shown in Fig. 3 when voltages collapse occurs.

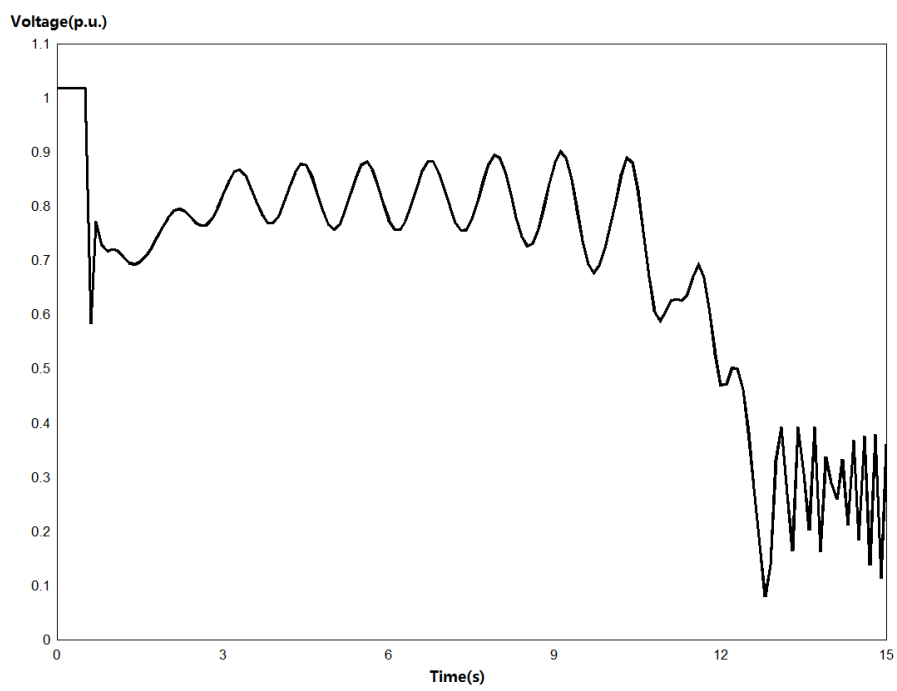

Fig. 3 The $500 \mathrm{kV}$ bus voltage variation in Ganzhou substation

(2) Connection mode B: Stability criterion level 1: No matter 500kV Fuhong line access or not, the system do not have voltage stability problem when any component "N-1".

Stability criterion level 2: Ganzhou power grid does not exist voltage stability problems with 500kV Fuhong line access. If 500kV Fuhong line do not put into operation, the system has the voltage stability problem only when the $500 \mathrm{kV}$ Wengan double circuit lines tripping without stability control measures. The voltage instability curve of Ganzhou $500 \mathrm{kV}$ bus is similar as Fig. 3.

\section{Summary}

(1) In the view of stability analysis, the influence of $220 \mathrm{kV}$ Wanluo substation access into Wanyan line is similar as the scheme access into Leiyan line. But the scheme access into Wanyan line is better because the overload is lesser and lighter.

(2) $500 \mathrm{kV}$ Fuhong line access or not has a great impact on stability analysis results. If Fuhong line cannot put into operation in 2016 under heavy load, the "N-1" and "N-2" problems will exist in Ganzhou area, which will affect regional power supply.

(3) In Ganzhou area, the problem of voltage stability is not outstanding. Only under the situation of $500 \mathrm{kV}$ Fuhong line not putting into operation, the system will the voltage stability problem when the $500 \mathrm{kV}$ Wengan double circuit lines tripping without stability control measures.

\section{References}

[1] C.J. Luo, X.W. Xiong, G. Wang, Calculation and analysis on security and stability of central china power grid in 2010 2011, J. Central China Electric Power. 23(2) (2009) 26-31.

[2] Y.X. Zhang, C.Y. Zheng, R.P. Guo, Risk analysis and decision-support system of Ningbo power grid, J. Power System Protection and Control. 39(11) (2011) 90-94. 
[3] B.J. Li, Y.J. Fang, T.S. Xu, Review on Online Operational Security Risk Assessment of Power Systems, J. Automation of Electric Power Systems. 36(18) (2012) 171-177.

[4] C.L. Wang, Y. Zhao, J.Q. Zhou, Probabilistic evaluation of power system operational risk based on daily generation scheduling J. Automation of Electric Power Systems. 32(4) (2008) 6-10.

[5] S.S. Zhao, Z.G. Zhou, D.X. Zhang, Risk assessment index of dynamic stability for large-scale interconnected grids and its application J. Power System Technology. 33(2) (2009) 68-72. 